\title{
Melanoma Review: Epidemiology, Risk Factors, Diagnosis and Staging
}

\section{Rodrigo Arrangoiz", Joel Dorantes, Fernando Cordera, Manuel Muñoz Juarez, Eduardo Moreno Paquentin, Enrique Luque de León}

Sociedad Quirúrgica S.C. at the American British Cowdray Medical Center, Mexico City, Mexico

Email address:

rodrigo.arrangoiz@yahoo.com (R. Arrangoiz),joeldorantes@yahoo.com (J. Dorantes), fernando.cordera@gmail.com (F. Cordera), munozmd1@gmail.com (M. M. Juarez),1morenomd1@gmail.com (E. M. Paquentin), enrique.luque.dl@gmail.com (E. L.de León)

${ }^{*}$ Corresponding author

\section{To cite this article:}

Rodrigo Arrangoiz, Joel Dorantes, Fernando Cordera, Manuel Muñoz Juarez, Eduardo Moreno Paquentin, Enrique Luque de León. Melanoma Review: Epidemiology, Risk Factors, Diagnosis and Staging. Journal of Cancer Treatment and Research.

Vol. 4, No. 1, 2016, pp. 1-15. doi: 10.11648/j.jctr.20160401.11

Received: February 22, 2016; Accepted: March 8, 2016; Published: April 21, 2016

\begin{abstract}
Study Aim: Cutaneous melanoma accounts for approximately 4\% of all skin cancers diagnosis each year in the USA but is responsible for $75 \%$ of skin cancer deaths. Physicians need to have an up to date knowledge about the epidemiology, risk factors, and clinical features of melanoma in order to make an early diagnosis and provide appropriate management decisions to improve survival in this aggressive malignancy. We will be presenting an extensive, up to date, literature review of cutaneous melanoma including the epidemiology, risk factors, diagnosis and staging. Method: An extensive literature review was performed using the following search engines: Pubmed, Ovid, Miromedex, and Dynamed. We limited our literature search to research papers written in English using the following keywords: cutaneous melanoma, epidemiology of melanoma, risk factors for melanoma, diagnosis of melanoma, clinical classification and staging of melanoma. Results: As a result of our extensive literature review we present an up to date review on the epidemiology, pathogenesis, risk factors, diagnosis, classification and staging of cutaneous melanoma. Conclusion: Physicians need to have an up to date knowledge about the epidemiology, risk factors, and clinical features in order to make an early diagnosis and provide appropriate management decisions in order to improve the survival patients with this aggressive malignancy.
\end{abstract}

Keywords: Cutaneous Melanoma, Epidemiology of Melanoma, Risk Factors for Melanoma, Diagnosis of Melanoma, Clinical Classification and Staging of Melanoma

\section{Introduction}

Cutaneous malignancies constitute one of the most commonly diagnosed cancers in the United States of America (USA), more than half of all cancers diagnosed each year [1]. In the USA, approximately 1.2 million to 1.4 million cases of skin cancer are diagnosed annually [1]. The most common skin cancer types are basal cell carcinoma (BCC), squamous cell carcinoma (SCC), and melanoma of the skin [1].

In the year 2015 an estimated 73,870 new cases of melanoma will be diagnosed (Table 1) [2]. The incidence is increasing dramatically, at an overall rate of $33 \%$ for men and $23 \%$ for women from 2002 to 2006 (about $2.6 \%$ per year) [3, 4]. These estimates for new cases may represent a substantial underestimation because many superficial and in-situ melanomas treated in the outpatient setting are not reported. There will be approximately 9,940 deaths in the USA secondary to cutaneous melanoma in 2015 [3]. Approximately 8000 patients will be found to have metastatic melanoma at the time of diagnosis [5]. Cutaneous melanoma accounts for four percent of all skin cancer diagnosis, but accounts for $75 \%$ of skin cancer deaths [6].

The age-adjusted incidence of invasive melanoma in the USA increased from approximately 4 per 100,000 to 18 per 100,000 in white males between 1973 and 1998 [7]. The incidence of melanoma continues to increase dramatically; melanoma is increasing in men more rapidly than any other malignancy and, in women more rapidly than any other 
malignancy except lung cancer [3]. This disturbing increase in the incidence of melanoma can largely be attributed to prevailing social attitudes toward sun exposure. Roughly
$86 \%$ of melanomas can be ascribed to exposure to ultraviolet (UV) radiation from the sun [8].

Table 1. Estimated Number of New Cancer Cases and Deaths by Sex, US, 2015.

\begin{tabular}{|c|c|c|c|c|c|c|}
\hline & \multicolumn{3}{|c|}{ Estimated New Cases } & \multicolumn{3}{|c|}{ Estimated Deaths } \\
\hline & Both Sexes & Male & Female & Both Sexes & Male & Female \\
\hline All Sites & 1658370 & 848200 & 810170 & 589430 & 312150 & 227280 \\
\hline Digestive system & 291150 & 163050 & 128100 & 149300 & 86540 & 62760 \\
\hline Respiratory system & 240390 & 130260 & 110130 & 1162460 & 89750 & 72710 \\
\hline Bones and joints & 2970 & 1640 & 1330 & 1490 & 850 & 640 \\
\hline Soft tissue (including heart) & 11930 & 6610 & 5320 & 4870 & 600 & 2270 \\
\hline Skin (excluding basal and squamous) & 80100 & 46610 & 33490 & 13340 & 9120 & 4220 \\
\hline Melanoma of skin & 73870 & 42670 & 31200 & 9940 & 6640 & 3300 \\
\hline Other nonepthelial skin & 6230 & 3940 & 2290 & 3400 & 2480 & 920 \\
\hline Breast & 234190 & 2350 & 231840 & 40730 & 440 & 40290 \\
\hline Genital system & 3329330 & 231050 & 98280 & 58670 & 28230 & 30440 \\
\hline Urinary system & 138710 & 96580 & 42130 & 30970 & 2110 & 9860 \\
\hline Nervous system & 22850 & 12900 & 9950 & 15320 & 8940 & 6380 \\
\hline Endocrine system & 64860 & 16520 & 48340 & 2890 & 1350 & 1540 \\
\hline Lymphoma & 80900 & 44950 & 35950 & 20940 & 12140 & 8800 \\
\hline Myeloma & 26850 & 14090 & 12760 & 11240 & 6240 & 5000 \\
\hline Leukemia & 54270 & 30900 & 233700 & 24450 & 14210 & 10240 \\
\hline Other and unespecified primary sites & 31510 & 16660 & 14850 & 43840 & 24480 & 19360 \\
\hline
\end{tabular}

C2015, American Cancer Society, Inc., Surveillance Research

One in five Americans will develop skin cancer in the course of a lifetime [9]. By 2015, it is estimated that one in 50 Americans will develop melanoma in their lifetime $[6,9$, 10]. Currently one USA citizen dies of melanoma every hour (every 57 minutes) [6]. Melanoma is the most common form of cancer of any type in women between 25 and 29 years of age and is the second most frequent cancer (after breast cancer) in white women aged 24-30 years with fair skin [11]. The lifetime risk of developing melanoma for someone born in the USA in the year 2000 is one in 41 for men and one in 61 for women $[11,12]$.

Although melanoma is the fourth and sixth most common malignancy in men and women respectively [3], melanoma ranks second to adult leukemia in terms of loss of years of potential life per death. An average of 18 life-years are lost for each melanoma death [13]. The increasing rate of melanoma incidents, tripled from 1980 to 2003, and it is not associated with a corresponding increase in melanoma deaths [14]. Since 1980 there has been no evidence of a linear trend in melanoma deaths, probably as the result of earlier detection and better treatment. Melanoma survival increased from $49 \%(1950-1954)$ to $92 \%(1996-2003)$ [15].

\section{Pathogenesis}

Environmental exposure (UV light) plus genetic susceptibility (CDKN2A, CDK4, MC1R, BRAF, p16/ARF genes) leads to the accumulation of genetic mutations in melanocytes that activate oncogenes, inactivate tumor suppressor genes and impair DNA repair mechanisms. This leads to melanocyte proliferation, blood vessel growth, tumor invasion, evasion of immune response, and ultimately metastasis [16].

Melanoma tumor progression based on Clark model depicts a slow but steady progression from benign melanocytic nevi to metastatic melanoma. The progression begins with a controlled proliferation of normal melanocytes to yield a benign nevus. The evolution continues with an abnormal growth of the melanocytes in a pre-existing nevus or in a new location resulting in a pre-malignant lesion with random cytologic atypia, this is refereed to atypical/dysplastic nevi. These lesions appear as flat macules, greater than five $\mathrm{mm}$ in size, with irregular borders, and variable pigmentation. With time the melanocytes acquire the ability to proliferate horizontally in the epidermis (radial growth) and histologically show continuous atypia (melanoma in situ). E-cadherin helps confine the cells intraepidermally but a few cells may invade the papillary dermis. Numerous biochemical events including the loss of Ecadherin and expression of $\mathrm{N}$-cadherin allow malignant cells to invade the basement membrane and proliferate vertically in the dermis as an expanding nodule with metastatic potential (vertical growth). Malignant melanocytes spread to other areas of body, usually first to lymph nodes then to skin, subcutaneous soft tissue, lungs and the brain (metastatic melanoma) [16] (Figure 1). 


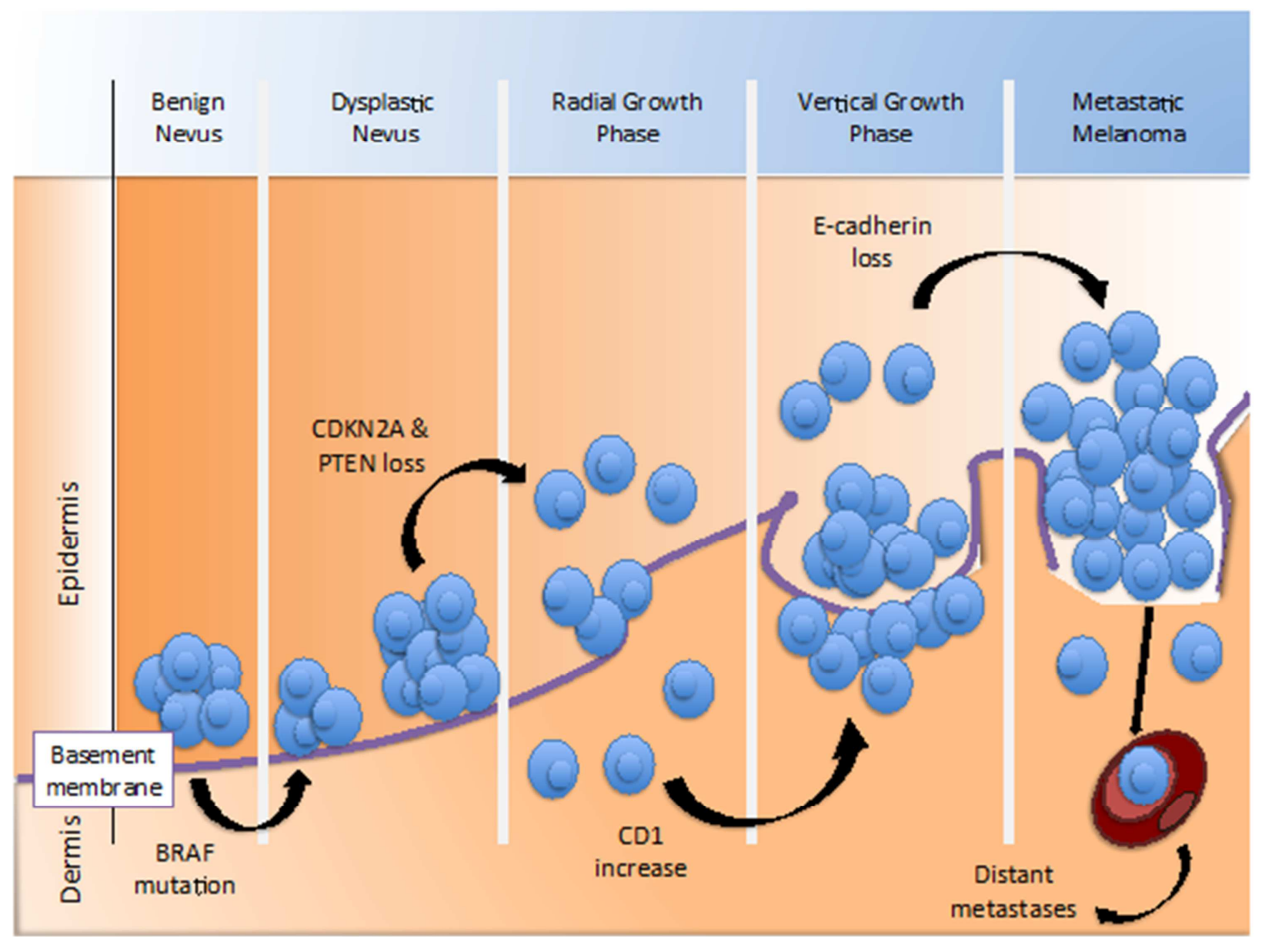

Figure 1. Melanoma Tumor Progression.

Ultraviolet (UV) radiation causes formation of pyrimidine dimers between adjacent thymine (T) and cytosine $(\mathrm{C})$ bases in DNA. Regions containing cytosine bases are hotspots for $\mathrm{C} \rightarrow \mathrm{T}$ transition, the most common type of UVB-induced mutation. DNA excision repair is an endogenous system that cuts out the dimers and replaces them with the original sequence. Xeroderma Pigmentosum is an inherited genetic disease with a dysfunctional DNA excision system, predisposing these individuals to melanoma [17, 18] (Figure 2).

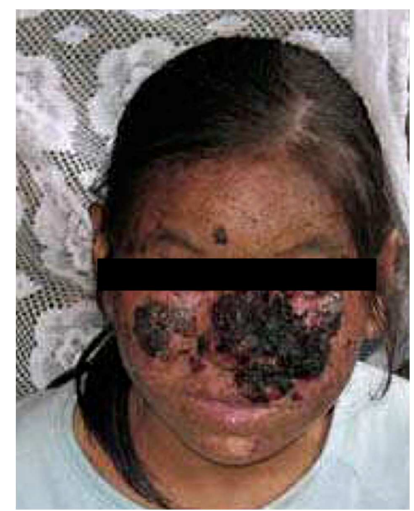

Figure 2. Xeroderma Pigmentosum.

\section{Etiology and Risk Factors for Malignant Melanoma}

Risk factors for cutaneous melanoma are both genetic and environmental with interaction between the two playing a critical role. The majority (approximately 90\%) of melanoma cases are sporadic. The main environmental risk factor associated with cutaneous melanoma is exposure to UV radiation $[8,19]$. There is sufficient evidence that too much exposure to solar UV radiation is the main cause of both malignant melanoma and non-melanoma skin cancers in humans, according to the International Agency for Research on Cancer (IARC) [19, 20]. A history of more than ten severe and painful sunburns is associated with a two-fold greater risk of developing melanoma [21]. Intermittent sun exposure, defined as, sporadic and commonly associated with recreational activities, particularly among indoor workers who use weekend or vacation time to be outdoors and whose skin has not adapted to the sun, is the most important risk factor for melanoma [22, 23] (Figure 3). Three systematic reviews have demonstrated similar estimates for the role of intermittent sun exposure in melanoma development (i.e., odds ratios [ORs] of 1.6 to 1.7) [24-26].

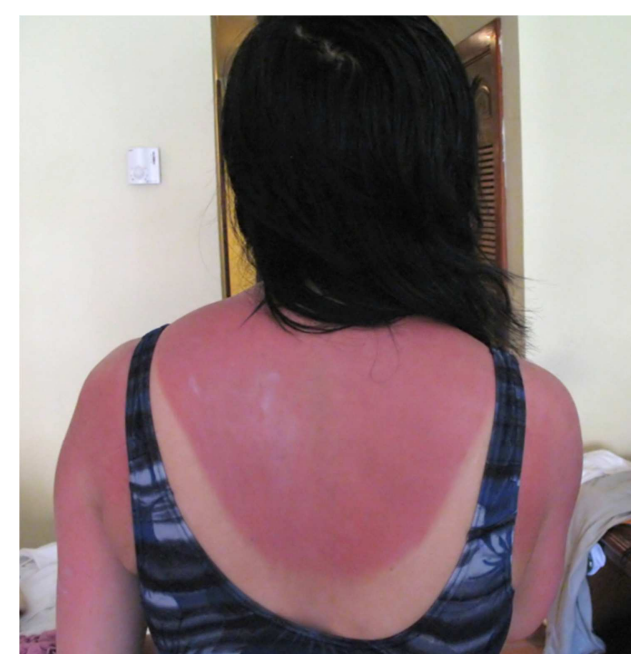

Figure 3. First Degree Sunburn. 
Pigment characteristics are important determinants of melanoma susceptibility. There is an inverse correlation between melanoma risk and skin color that goes from lightest skin to darkest skin. Melanoma occurs infrequently in skin of color, suggesting that skin pigment plays a protective role [27]. Melanoma is 10 to 12 times more common in whites, and 6 to 7 times more common in Hispanics than in African Americans (AA) [27]. Fair complexion (Fitzpatrick skin photo-type I and II) [28], blue or green eyes, blond or red hair, freckling are all risk factors for the development of melanoma $[23,29,30]$. A recent meta-analysis reported, that in contrast with people with Fitzpatrick skin photo-type IV, those with Fitzpatrick skin photo-type I are at more than double (2.27 times) the risk, photo-type II at double (1.99 times) the risk, and photo-type IIIa $35 \%$ increased risk for developing malignant melanoma [31]. People with red/redblonde hair have triple the malignant melanoma risk compared to dark-haired people [31, 32]. People with blond hair are at double the risk, and people with light brown hair are at $46 \%$ increased risk [31]. Individuals with freckles have double (1.99 times) the risk of malignant melanoma, as opposed to people without freckles [31]. These individuals with freckles have increased malignant melanoma risk, irrespective of the number of moles they have [33]. Individuals with blue/green-blue/green-grey eyes are at increased risk of basal cell carcinoma (BCC) [34] [35-37], the risk for melanoma is less well known.

The incidence of melanoma is subject to large geographic and ethnic variations, mainly because of an inverse correlation with latitude and with degree of skin pigmentation. Populations residing closer to the equator have a higher incidence of melanoma. Among relatively lightskinned individuals, skin color is modified by genetics and behavior. $M C 1 R$ is one of the major genes controlling pigmentation; other pigmentation genes are under investigation [27].

The incidence of melanoma increases with age [38]. The incidence of melanoma is 1.7 fold higher in women than in men before the age of 39 [6]. Women 39 years of age and under have a higher probability of developing melanoma than any other cancer except breast cancer [6]. The incidence of melanoma is 2.2 fold higher in men than in women older than 70 years of age [39]. Melanoma incidence is higher in men than in women, specifically a mans risk of developing melanoma over his lifetime is 1.5 times greater than a women's risk [6].

Exposure to tanning beds increases the risk of melanoma, especially in women aged 45 years or younger [40]. In females between 15 to 29 years of age, the torso/trunk is the most common location for developing melanoma, which may be due to high-risk tanning behaviors [41, 42]. In 2009, the World Health Organization International Agency for Research on Cancer classified UV light emitted from tanning beds as a human carcinogen [43]. More than 170,000 cases per year of non-melanoma skin cancers in the US are related with indoor tanning [44]. In the US approximately 30 million people tan indoors every year [45]. Two to three million of them are teens [46]. One indoor UV tanning session increases ones' risk of developing squamous cell carcinoma (SCC) by $67 \%$ [44], BCC by $29 \%$ [44], and melanoma by $20 \%$, and each additional session during the same year increases the risk almost another two percent [47].

More than $90 \%$ of the visible changes commonly attributed to skin aging are caused by the sun [48]. One example is actinic keratosis (solar keratosis) (Figure 4), which is a premalignant neoplasm of the epidermis caused by excessive exposure to sunlight and manifesting as an ill defined, irregular, erythematous, scaling, rough papule or patch.

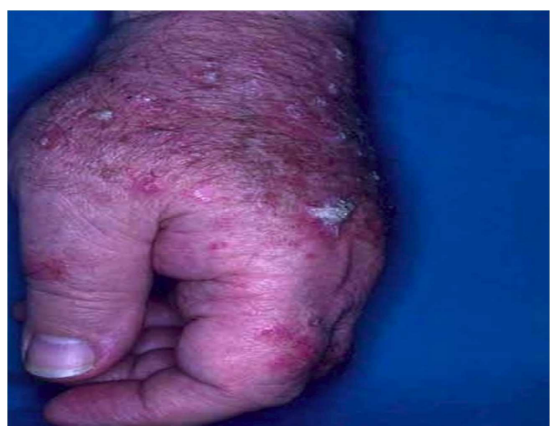

Figure 4. Actinic Keratosis.

Nevi are benign melanocytic neoplasms found on the skin of most people. They usually appear by 4 to 5 years of age, increase in pigmentation during puberty, and involute in the elderly population (seventh to eight decade of life). Nevi may occur anywhere on the body, including the nails, palms, and soles. Nevi may be raised or flat. There color may vary from pink to skin-colored to brown, but they may be darker in people with normally darker skin. Non-cancerous (benign) nevi are usually alike on both sides (symmetrical), have smooth, regular borders, and homogenous color, and they are generally smaller than the size of a pencil eraser $(6 \mathrm{~mm})$ [49].

Dysplastic nevi are less common. They contain a histologically identifiable focus of atypical melanocytes [50]. This type of nevus may represent an intermediate step between a benign nevus and a true malignant melanoma. The relative risk of developing melanoma increases with the number of dysplastic nevi that a patient has. The relationship is similar to that between the number of colonic polyps and the development of colon cancer. Most nevi are genetically determined though sun exposure can increase the number of nevi [51]. The emergence of nevi in adolescents is under strong genetic control [52]. Chronic sun exposure rather than number of sunburn episodes is the most important environmental factor determining nevi development [33].

It is well documented that patients with melanoma have significantly more nevi and dysplastic nevi than matched controls. Adults with more than 100 clinically normalappearing nevi and children with more than 50 clinically normal-appearing nevi, and any patient with atypical or dysplastic nevi are at risk of developing melanoma [50, 53] (Figure 5). Meta-analyses of individuals with any large or unusually shaped nevi have around four to ten times 
increased risk of malignant melanoma [54, 55] and the risk increases with the number of atypical nevi [54]. An atypical nevus is not a pre-melanoma but represents a genetic marker for increased risk of development of a melanoma, which may occur anywhere on the skin surface including sun-protected sites. In fact, more than $50 \%$ to $75 \%$ of melanomas develop on clinically normal skin de novo not in preexisting melanocytic lesions [56].

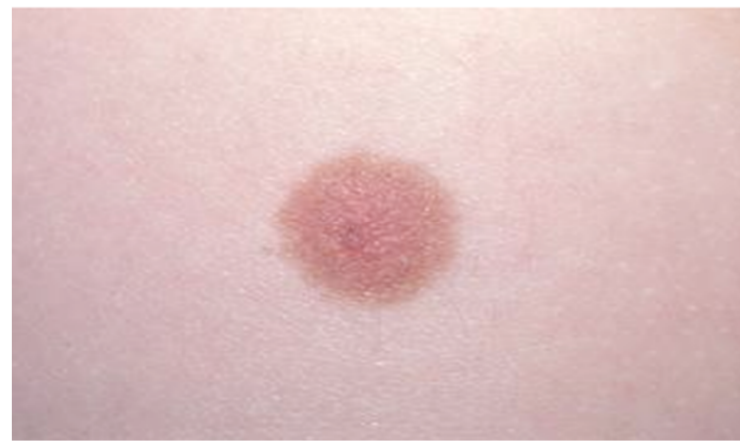

Figure 5A. Normal Appearing Nevi.

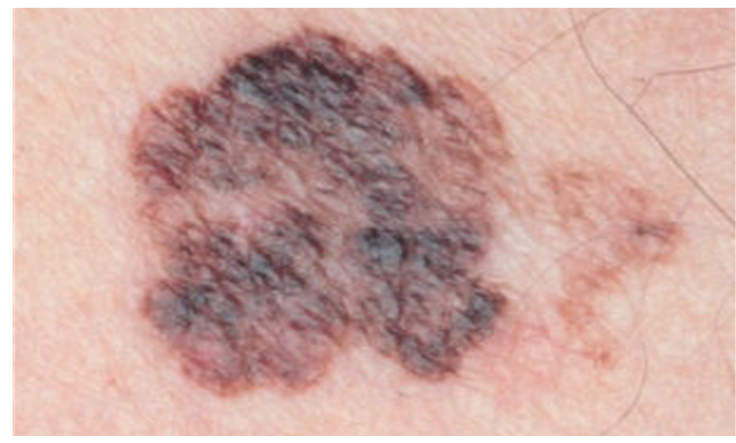

Figure 5B. Atypical Nevi.

Members afflicted with the B-K mole syndrome, named after the first two families in which this syndrome was first identified have large, irregular, and dysplastic nevi often in sun-protected regions of the body, such as the scalp and trunk. This syndrome is inherited as an autosomal dominant trait. Patients with B-K mole syndrome have been known to have a very high risk for the development of cutaneous melanoma and multiple primary malignancies. They may be a propensity in these patients for development of ocular melanomas [57-59] (Figure 6).

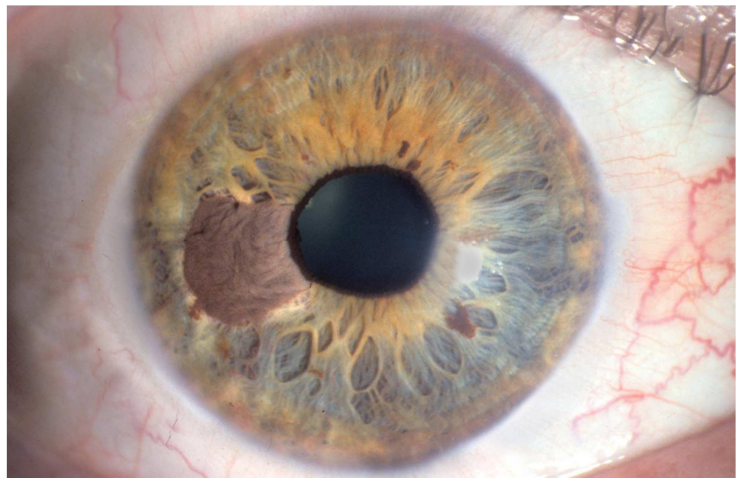

Figure 6. B-K Mole Syndrome.
Lynch et al. independently reported a familial association of melanoma among individuals with atypical nevi $(>5 \mathrm{~mm}$ in sun protected regions of the body), which he termed Familial Atypical Multiple Mole-Melanoma Syndrome, or FAMMM syndrome, with an autosomal dominant inheritance pattern. Fifty-six percent of patients with FAMMM develop melanoma between 20 and 59 years of age and $100 \%$ of atypical mole syndrome patients developing melanoma by age 76 [59]. This syndrome is this is very rare and accounts for less than $5 \%$ of malignant melanoma cases [54]. FAMMM is associated with the hereditary susceptibility genes CDKN2A and CDK4. CDKN2A mutation carriers often have three or more family members with malignant melanoma, or have multiple primary malignant melanomas with no family history. CDKN2A mutation carriers living in Europe have an approximately 58\% risk of developing malignant melanoma by age $80[60,61]$.

A prior history of melanoma places a patient at increased risk with $3 \%$ to $10 \%$ of individuals developing a second primary melanoma [61]. The risk is 900 times that of the general population [62]. This risk of developing a second primary melanoma is life-long and can occur anywhere on the skin, therefore, long-term surveillance with a thorough total body examination is recommended [62]. The effect is stronger for women [61, 62]. Individuals with a previous melanoma and a parent with a melanoma are at more than 30 fold risk of a second malignant melanoma [62]. Melanoma risk is higher among individuals with previous other cancer diagnosis, including female breast cancer [63, 64]; renal cell carcinoma [65]; non-Hodgkin lymphoma [66, 67]; certain childhood cancers [68]; prostate cancer [63]; thyroid cancer [63]; and leukemia [63]. Usually the increase risk is less than double. Frequently these associations are bi-directional [62], supporting shared genetic or environmental factors.

Of patients with melanoma, $8 \%$ to $15 \%$ report a positive family history $[69,70]$. The most common chromosomal mutation associated with melanoma involves CDKN2A, also known as p16 (tumor suppressor gene). However, the mutation accounts for only a small percentage of melanoma cases observed (estimated at $0.2 \%$ ). The mutated gene is found in $90 \%$ of the cases of inherited melanoma, it is found on chromosome 9p21 [71]. This gene codes for the cyclindependent kinase inhibitor 2 (CDKN-2), which controls passage of cells through the G1 phase of the cell cycle [72]. Loss of this inhibition may lead to uncontrolled entry into the G1 phase. A population-based study investigating the lifetime risk of melanoma among carriers of cyclindependent kinase 2A mutations evaluated 3550 probands from 9 geographic areas throughout Australia, Canada, and the United States. The results showed the risk to be $14 \%$ (95\% confidence interval: $8 \%$ to $22 \%$ ) by 50 years of age, $24 \%$ (95\% confidence interval: $15 \%$ to $34 \%$ ) by 70 years of age, and $28 \%$ ( $95 \%$ confidence interval: $18 \%$ to $40 \%$ ) by 80 years of age. These estimates are in contrast to an approximate $2 \%$ lifetime risk of melanoma among the general population in these regions [71].

The MC1R gene mutation is clearly a risk factor for 
cutaneous melanoma. The $M C 1 R$ gene provides commands for making a protein called the melanocortin 1 receptor [73]. This receptor plays a role in normal pigmentation [74]. The receptor is primarily located on the surface of melanocytes [75]. Melanin is also found in the light-sensitive tissue in the retina, where it plays a role in normal vision. Numerous genetic alterations in the $M C 1 R$ gene increase the risk of developing skin cancer, including melanoma. Variations in the MC1R gene disrupt the ability of the melanocortin 1 receptor to trigger eumelanin production in melanocytes. Because eumelanin normally protects skin from the harmful effects of UV radiation, a lack of this pigment leaves fair skin more vulnerable to damage from the sun [76].

Research suggests that in the $M C 1 R$ gene may also increase the risk of developing melanoma in the absence of UV radiation-related skin damage. In these cases, melanomas can occur in people of dark or light skin coloring. These cancers are often associated with mutations in additional genes related to melanoma risk, such as the $B R A F$ and $C D K N 2 A$ genes [77]. The combination of MC1R mutation and red hair is associated with a very high risk of melanoma development [78]. Within melanoma families, defined as kindred's in which melanoma occurred in 2 or more blood relatives, the likelihood of developing melanoma is even greater among those family members who have dysplastic nevi [79].
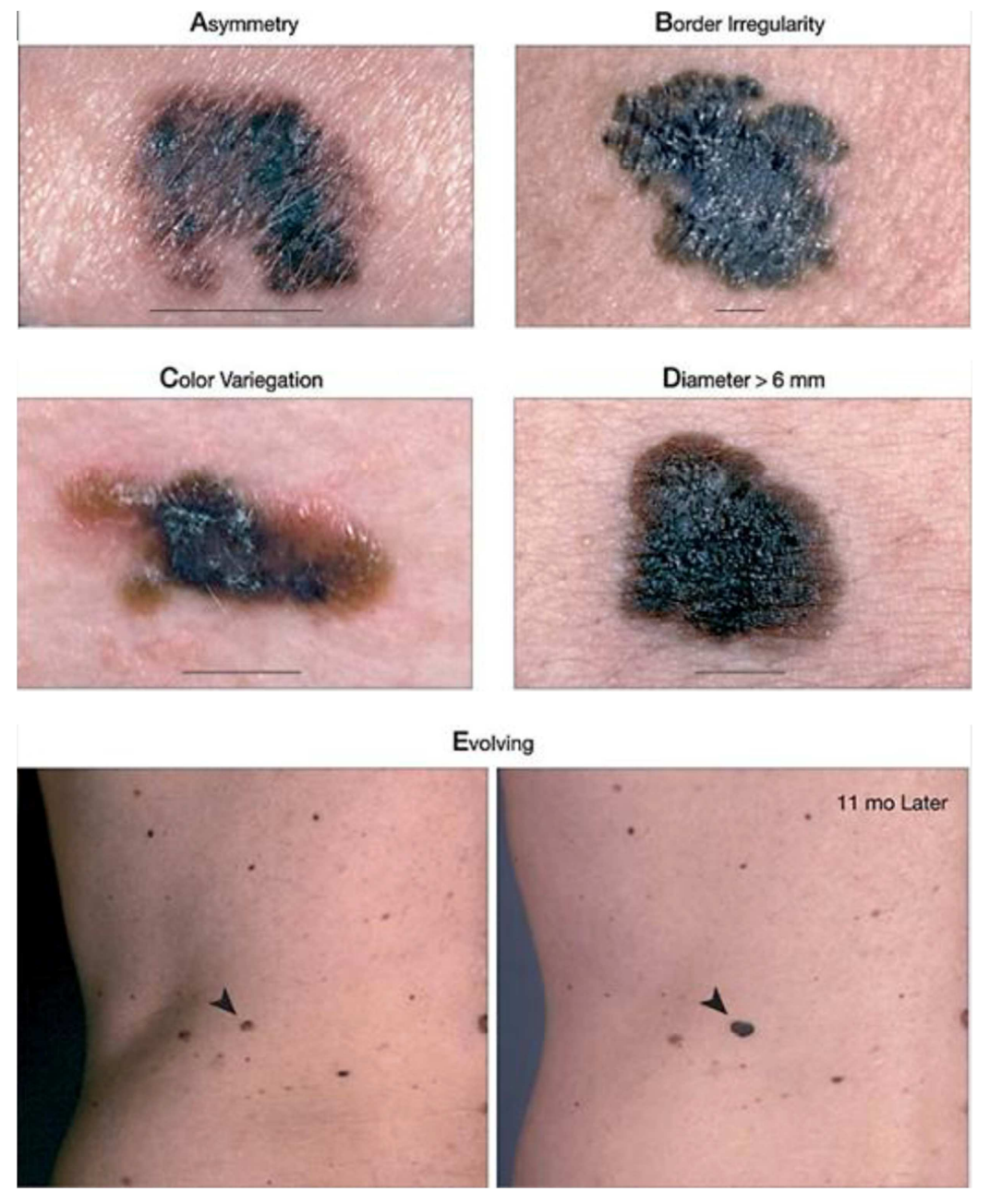

Figure 7. The acronym ABCDE represents a systematic method for the evaluation of pigmented lesions according to it clinical features.

Malignant melanoma and non-melanoma skin cancers have been linked to Li Fraumeni syndrome in some studies, although they are not among the 'essential' cancers occurring in Li Fraumeni families [80].

\section{Clinical Diagnosis}

Cutaneous melanoma arises from transformed melanocytes and can appear anywhere that melanocytes have migrated from during embryogenesis. The eyes [81], central nervous system [82], gastrointestinal tract [83, 84], and even the gallbladder [85] have been reported as primary sites of the disease. More than $90 \%$ of melanomas are found on the skin and four percent are discovered as metastases without an identifiable primary site. Many melanomas, especially in the early phases of growth, are found to contain areas of tumor regression on histological examination (regression represents a host immune response to the tumor) that clinical resemble areas of discoloration in the pigmented lesion. Early detection is key and most melanomas have specific characteristics like: often occur on sun-exposed areas of the upper trunk and the extremities, they are typically asymmetric, with irregular borders, variation in pigmentation, greater than $6 \mathrm{~mm}$ in size, may be elevated, evolving or enlarging [49].

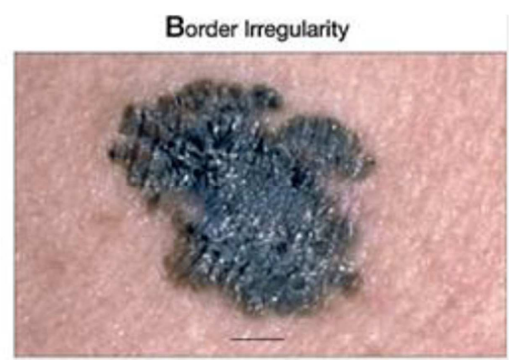

ving 
The goal of any diagnostic aid is early detection, the ability to differentiate between benign and malignant lesions, with $100 \%$ sensitivity combined with high specificity, this is something very difficult to achieve. Currently the optimum diagnostic aid that combines $100 \%$ sensitivity and specificity currently does not exist. In 1985 the acronym, ABCD, was introduced and in the year 2004 it was later expanded to ABCDE. It represents a systematic method for the evaluation of pigmented lesions that clinicians and the general public can utilize to help detect cutaneous melanoma at an early stage [86]. Melanoma often presents clinically with some or all of the $\mathrm{ABCDE}$ features, specifically asymmetry (A), border and surface irregularity (B), color variability (C), diameter greater than $6 \mathrm{~mm}(\mathrm{D})$, and evolution or change (E) [49]. Nevertheless, clinicians diagnosing potential skin cancers face the task of trying to distinguish cutaneous melanoma from many other clinically atypical nevi, which also often display some or all of the ABCDE criteria. One thing to take into consideration is that by solely relying on the $\mathrm{ABCDE}$ pneumonic many cutaneous melanomas that are smaller than $6 \mathrm{~mm}$ in diameter or that lack the ABCDE criteria may be overlooked [87] [49] (Figure 7).

The 7-point checklist was developed in Glasgow in the 1980s to help non-dermatologists detect features indicating possible cutaneous melanoma, with the instruction that each feature should score 1 point and lesions with scores of $\geq 3$ should be referred to the specialist [88]. The checklist was adopted and widely disseminated by the Cancer Research Campaign to raise public awareness, but there were fears that it under-identified early and nodular melanomas and overidentified certain benign lesions such as seborrheic keratosis [89]. The 7-point checklist was revised in 1989 to identify three major signs (change in size, shape and/or color) and four minor signs (inflammation, crusting/bleeding, sensory change, diameter $\geq 7 \mathrm{~mm}$ ) for suspected malignant melanoma; the scoring was weighted ( 2 for major, 1 for minor signs), and again, any lesion scoring $\geq 3$ warranting referral [90]. The 7-point checklist was recommended for use by all primary care professionals in the evaluation of pigmented skin lesions by the 2005 English National Institute for Health and Clinical Excellence (NICE) guidelines on referral for suspected cancer. Any lesions scoring $\geq 3$, suggestive of possible melanoma, should be referred urgently [91] (Table 2).

Table 2. Glasgow Seven Point Checklist.

\begin{tabular}{ll}
\hline Major Features & Minor Features \\
\hline - Change in Size & - Diameter $\geq 7 \mathrm{~mm}$ \\
- Change in Shape & - Inflammation \\
- Change in Color & - Crusting / Bleeding \\
& - Mild Itch or Altered Sensation \\
\hline
\end{tabular}

Grob, et al. [92], in 1998, introduced the ugly duckling concept. This concept was based on the observation that nevi in the same individual tend to be similar to one another, and that cutaneous melanoma often deviates from this nevus pattern. This clinical understanding pointed to the importance of not just assessing the morphology of the lesion in question, but also comparing it to that of surrounding lesions, looking for an outlier in the background of similar-looking nevi. For example, the outlier lesion can be larger and darker than the surrounding moles or conversely, small and red in the background of multiple large dark moles. Lastly, if the patient has few or no other moles, any changing lesion should be considered a suspicious lesion. In conclusion any pigmented lesion that is different from the others should be carefully approached with a high index of suspicion (ugly duckling sign).

Three principle mental processes for image recognition have been described [93]: overall pattern recognition (known as gestalt); analytic criteria recognition (such as the ABCDEs); and differential recognition (recognizing the differences between objects, for example the ugly duckling concept). In their study, Gachon, et al. [93], surveyed dermatologists for perception parameters that triggered surgical removal of pigmented lesions. Differential recognition of the ugly duckling sign was more discriminatory between cutaneous melanoma (Figure 8) and other nevi than the ABCDE criteria [93].

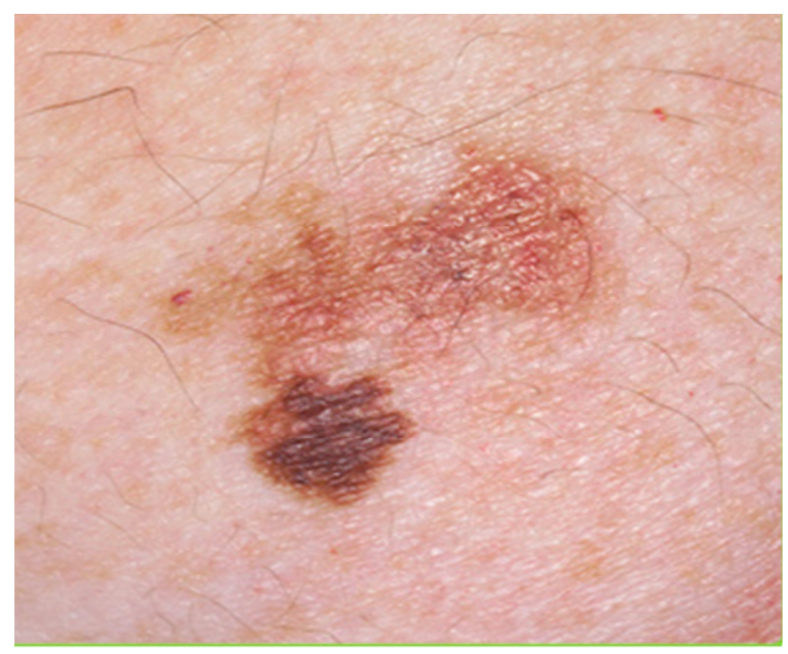

Figure 8. Cutaneous Melanoma.

The introduction of dermoscopy has improved the diagnostic armamentarium of physicians with new morphological clues that are particularly helpful for bettering the early detection of cutaneous melanoma. In a metaanalysis of dermoscopy studies performed in a clinical setting, the summary estimate of the sensitivity was higher for dermoscopy than for the naked-eye examination alone, $90 \%$ and $71 \%$ respectively, with specificities of $90 \%$ for dermoscopy and $81 \%$ for the naked-eye examination [94]. The use of all available means including the ABCDE acronym, the seven-point checklists, the ugly duckling sign, photography, dermoscopy, and evolving digital and computer-assisted imaging technologies enhances the ability to diagnose melanoma at the earliest stage (Figure 9). 


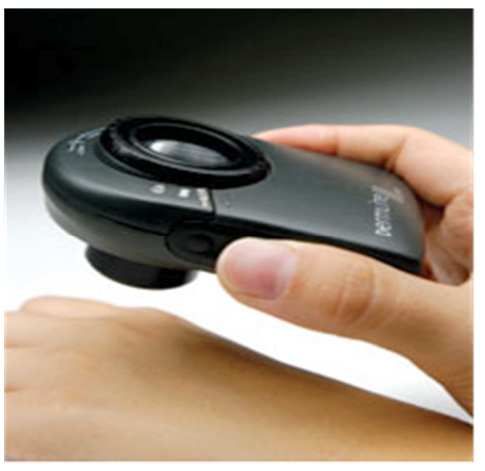

Figure 9. Dermoscopy has a higher sensitivity than for the naked eye examination alone in early detection of cutaneous melanoma.

Once a suspicious pigment lesion has been identified the next step is to obtain a tissue biopsy to confirm or refute the diagnosis of malignancy (Figure 10).
When feasible an excisional biopsy (elliptical, punch, or saucerization) with 1 to $3 \mathrm{~mm}$ margins is preferred [95]. One should avoid wider margins to permit accurate subsequent lymphatic mapping. The orientation of the biopsy should be planned with definitive wide excision in mind. An example are lesions on the extremities, the biopsy should be planned to be on the vertical / longitudinal plane of the extremity. For lesions excised in an ellipse of skin and fat, the length of the ellipse should be approximately 3.5 to 4 times the width to allow tension-free closure without dog-ears (Figure 11). In certain anatomic areas such as the palms/soles, distal digit, face, ear, subungual region or for very large lesions a full thickness incisional or punch biopsy may be preferred [95]. The biopsy needs to be taken from the clinically thickest or darkest portion of lesion. If clinical evaluation of incisional biopsy suggests that micro staging is inadequate, consider narrow margin excisional biopsy.

Suspicious Pigmented Lesion

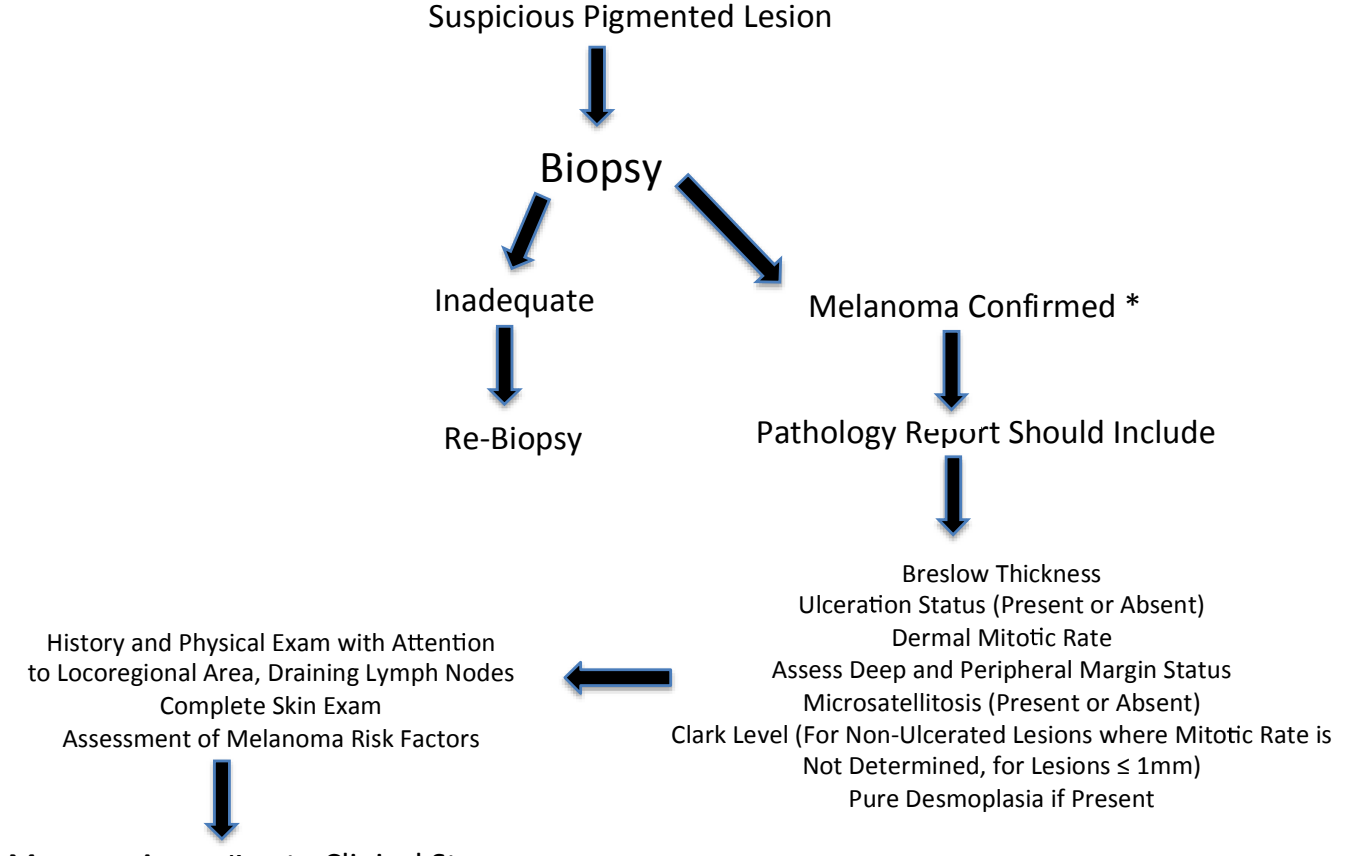

Manage According to Clinical Stage

*If diagnostic biopsy is inadequate for treatment decisions, re-biopsy my be appropriate

Figure 10. Diagnostic Work-Up.

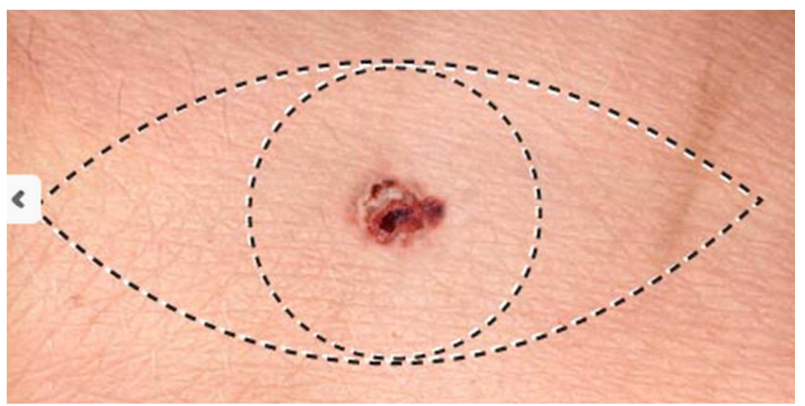

Figure 11. For lesion excised in an ellipse of skin and fat, the length of the ellipse should be approximately 3.5 to 4 times the width to allow tension-free closure.
Shaved biopsies may compromise pathologic diagnosis and complete assessment of Breslow thickness but is suitable when the index of suspicion is low [95]. When the index of suspicion is high a shave biopsy is discouraged because it may create a positive deep margin, thereby compromising determination of the true depth of penetration of a melanoma.

A pathologist experienced in pigmented lesions should read the biopsy specimens. Formalin-fixed, paraffinembedded, permanent sections should be used for diagnosis of primary cutaneous melanoma to determine accurately tumor thickness and other histopathologic prognostic variables such as: microsatellitosis, location, regression, tumor-infiltrating lymphocytes (TIL), vertical growth phase 
(VGP), angiolymphatic invasion, neurotropism (an ability to invade and live in neural tissue), and pure versus mixed desmoplasia [96].

Tumor regression is defined as the replacement of tumor tissue with fibrosis, degenerated melanoma cells, lymphocytic proliferation, and telangiectasia formation [97]. The incidence varies according to tumor depth, superficial tumors that measure $0.75 \mathrm{~mm}$ or less have a $58 \%$ incidence of regression [98]. Most studies have not found a significant role for regression in determining survival. One study, from the University of California at San Francisco Melanoma Center, showed that regression is an adverse prognostic factor in predicting survival in thin melanomas [99]. In this study tumors less than $1 \mathrm{~mm}$ with evidence of greater than $50 \%$ regression are recommended for a SLN biopsy to evaluate for spread to the regional lymphatic's.

TIL represents the body's immune response to melanoma cells. This response is usually measured by the level of lymphocytic infiltrate present at the base of the vertical growth phase of the tumor and is sometimes categorized as brisk, non-brisk, or absent. The 5-year survival rates for melanoma in a vertical growth phase with a brisk infiltrate is $77 \%$, with a non-brisk infiltrate is $53 \%$, and in the absence TIL is $37 \%$ [100].

Frozen sections analysis (FSA) has no role in the diagnosis or micro staging of primary melanoma [101-103]. The combination of the low sensitivity of FSA and a finding that only $12 \%$ of the sentinel lymph nodes (SLN) biopsied contained metastases does not justify routine use of FSA on the SLN of patients with cutaneous melanoma [104, 105].

\section{Classification}

Melanoma can be classified in several ways taking into account various variables such as histopathological type, vertical growth, whether it has spread to nearby lymph nodes or any other organ, among other factors.

Regarding the histopathological type, melanomas are characterized by their high morphological diversity. Although histologic subtype does not directly correlate with the clinical behavior, sub classifying is important for histopathological diagnosis and recognition. Four main histological patterns have been described. In descending order of frequency, they are: superficial spreading melanoma, nodular melanoma, lentigo maligna melanoma and acral lentiginous melanoma. [106, 107].

Superficial spreading melanoma (SSM) is the most common subtype, comprising approximately $75 \%$ of all malignant melanomas. [108]. A quarter of these types of melanomas are found in association with a preexisting nevus, while most developed de novo [108]. These melanomas get their name because they have a radial growth pattern for a period of time before their vertical growth occurs [109] (Figure 12). SSM are usually seen in white people and have a predilection for the trunk in men and lower limbs in women [110]. SSM clinically appears as a pigmented plate with irregular edges, ranging from a few millimeters to several centimeters in diameter [108]. SSM is typically characterized by variation in color, irregular borders and irregular surface, and often exhibits the classic melanoma clinical features [110]. Histologically SMM include a diffuse pagetoid pattern of radial growth phase (RGP). Epithelioid cells are the dominant type in the RGP, the dermis of the RGP ranges from normal to hyperplastic. Epithelioid cells are the dominant type in the vertical growth phase (VGP). Desmoplasia and neurotropism are rare and partial regression often occurs [111].
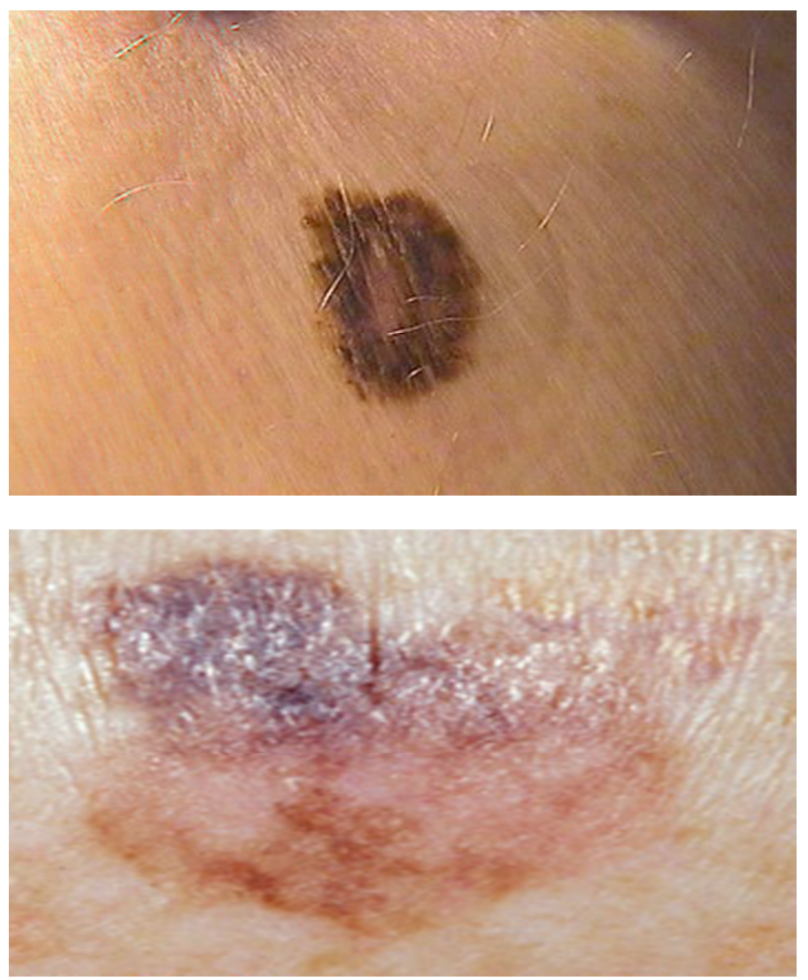

Figure 12. Superficial Spreading Melanoma.

Lentigo malignant melanoma (LMM) accounts for $4 \%$ to $15 \%$ of melanomas. Generally, it grows in areas of sundamaged skin in older individuals (mean age of 65 years, with peak incidence in the seventh to eight decades of life) and starts as a freckle-like, tan-brown macule (Hutchinson melanoma) $[112,113]$. Lentigo maligna (LM) represents in situ melanoma that in time may progresses to invasive lentigo maligna melanoma, in $5 \%$ to $8 \%$ of the cases. Most authors refer to it as LM when it is confined to the epidermis and LMM when it violates the dermis [112, 114] (Figure 13). Transformation is slow and the lesion can be present for 10 to 50 years before undergoing vertical growth. It appears in areas of the head and neck chronically exposed to sunlight, usually in individuals older than 50 years of age [112]. Histologically it has RGP pattern, the dominant cell type in RGP are epithelioid, spindle and uncommonly dendritic cells. The epidermis of RGP is usually atrophic, the dominant type of cell in the VGP are spindle and epithelioid cells. Desmoplasia, neurotropism and regression are common $[115,116]$. 

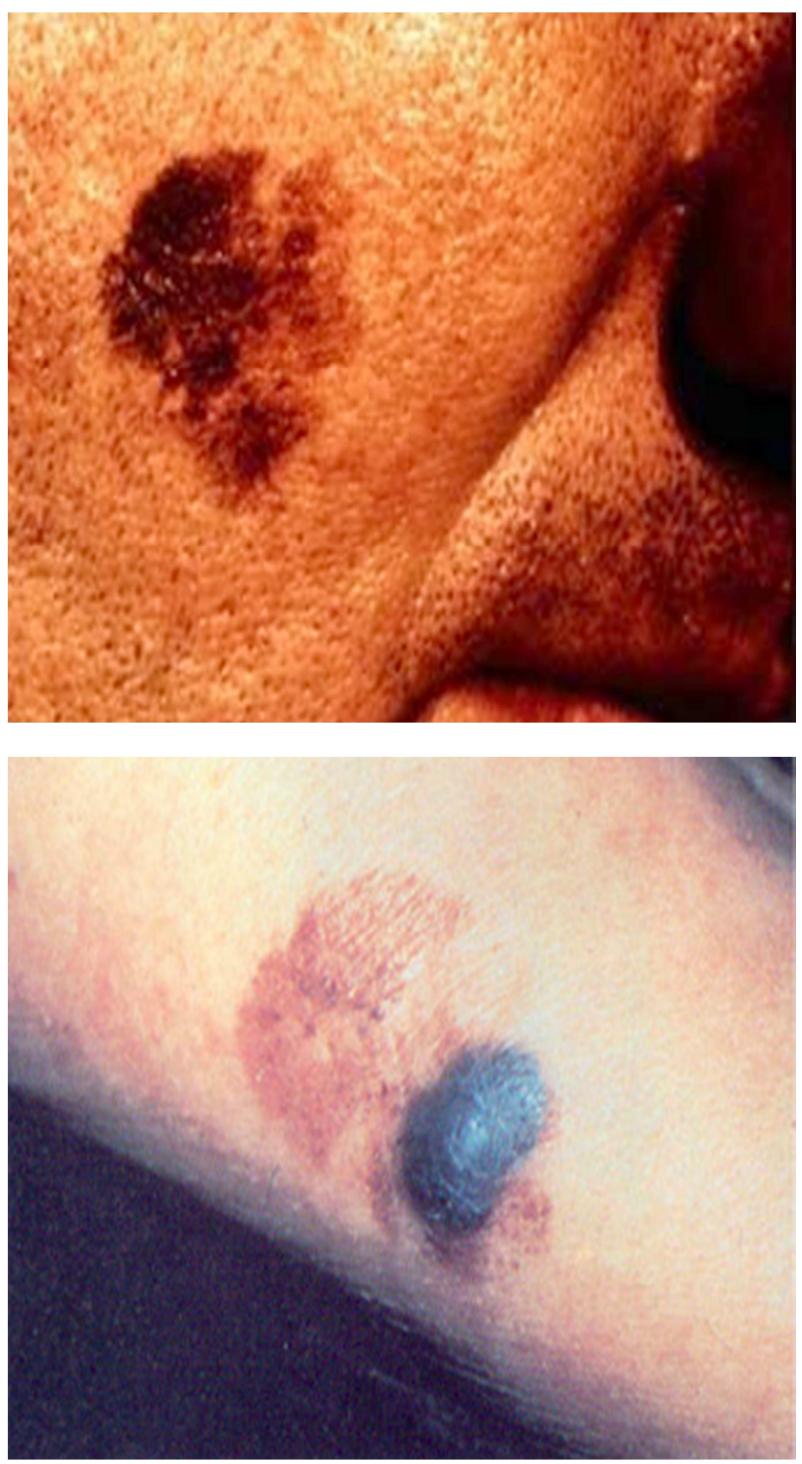

Figure 13. Lentigo Malignant Melanoma.

Acral lentiginous melanoma (ALM) is the least common variant, representing $2 \%$ to $8 \%$ of all melanomas in white people and $29 \%$ to $72 \%$ in dark skin population [108]. ALM commonly develop in palmar regions, plantar regions, and occasionally subungual surfaces. Often they are large (average diameter of $>3 \mathrm{~cm}$ ). Three quarters of subungueal melanomas are found in the great toe or thumb. [109] It is the most common subtype in Asian population and dark-skinned individuals. Subungueal melanoma arises from the nail matrix. The additional presence of pigmentation in the proximal or lateral nail folds (Hutchinson's sign) is diagnostic of subungueal melanoma $[109,115]$. Clinically appears as a dark brown to black color patch heterogeneously pigmented. Histologically is very similar to lentigo maligna melanoma, presenting a similar pattern of RGP. Lentiginous, spindle, epithelioid or dendritic cells are found in RGP and spindle and epithelioid cells in VGP. Desmoplasia and neurotropism are common. In contrast, the epidermis of the RGP is hyperplastic and the frequency of regression is variable [117, 118] (Figure 14).
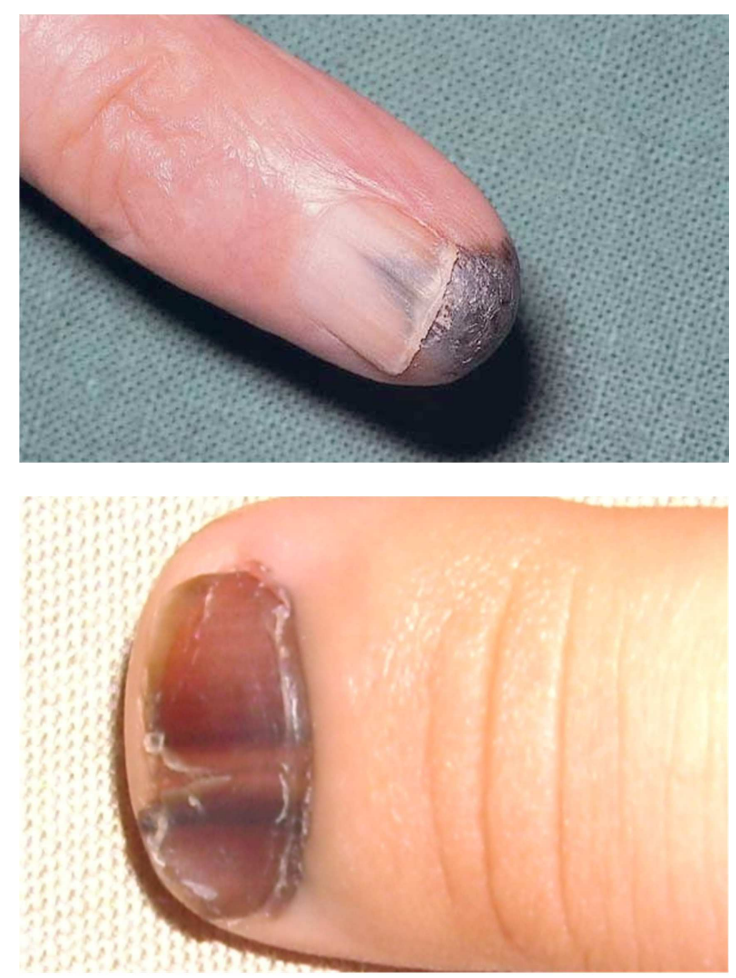

Figure 14. Acral Lentiginous Melanoma.

Histological criteria for nodular melanoma (NM) is the lack of a radial growth phase in the periphery around the area of vertical growth. Hence, all nodular melanomas are in the vertical growth phase at the time of diagnosis [112]. NM represent 15 to $30 \%$ of all melanomas. These lesions are darker and raised (dome shaped). They progress to invasiveness more quickly than any other type of melanoma. Although it is an aggressive lesion, the prognosis for a patient with a NM is the same as for an any other subtype stage for stage [112]. Clinically appears as a pigmented pedunculated nodular polyp. They may present without the classical characteristics of melanoma in the early stages, with regular edges, size less than $6 \mathrm{~mm}$ and uniform color. Change in size, shape or any morphologic difference is very important for early detection [108, 118]. Histologically the RGP pattern is absent, the dominant type cell in the VGP is epithelioid. Desmoplasia, neurotropism, and regression are not common (Figure 15).

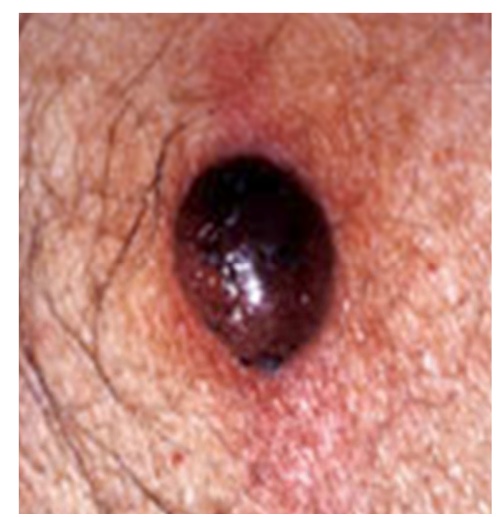




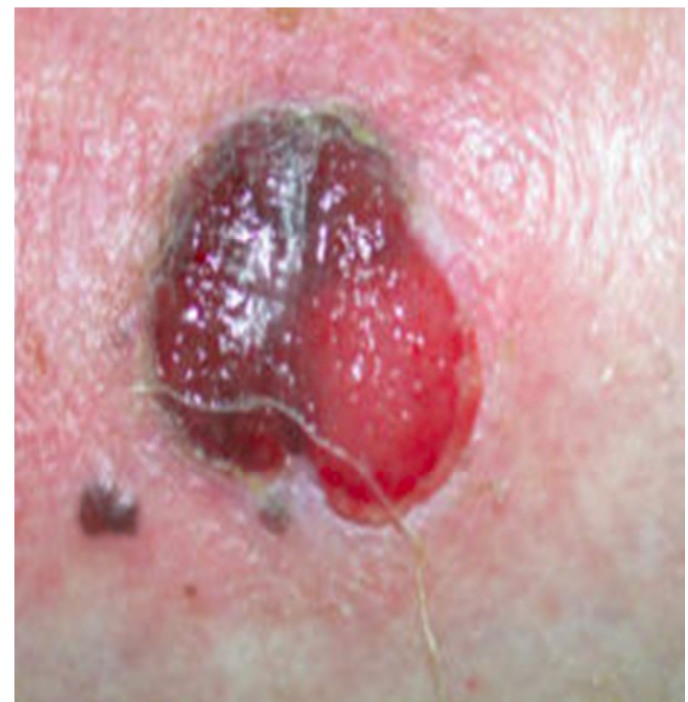

Figure 15. Nodular Melanoma.

Other less common subtypes of melanoma include demoplastic melanoma, epithelioid cell melanoma, spindle cell melanoma, balloon cell melanoma, malignant blue nevus melanoma, and malignant melanoma in giant pigmented nevus.

Neurotropic melanoma results in perineural invasion and expansion along peripheral nerves. Its microscopic appearance is characterized by patterns of Schwann and spindle cells that have poorly defined margins. It is difficult to diagnose this pattern as it can be confused with the sarcomatous lesions [119].

Desmoplastic melanomas, spindle cell melanomas and neurotropic melanomas, all tend to arise in similar clinical settings and are malignant tumors of the same cell type. Clinically, the lesions are usually found on the head and neck region and present as bulky firm fibrous masses or indurated plaques. These are usually amelanotic lesions [120].

Melanomas can be classified based on the degree of invasion through the different layers of the skin (VGP), such as Clark Level and Breslow Level, which correlate with fiveyear survival (Table 3 and Table 4) [111, 121]. The American Joint Committee on Cancer (AJCC) TNM Staging System for Melanoma is described in Table 5,6,7,8,9 [93].

Table 3. Clark Level.

\begin{tabular}{lll}
\hline $\begin{array}{l}\text { Clark } \\
\text { Level }\end{array}$ & Degree of Tumor Invasion & $\begin{array}{l}\text { 5-Year } \\
\text { Survival (\%) }\end{array}$ \\
\hline Level I & $\begin{array}{l}\text { Malignant melanocytes are confined to } \\
\text { epidermis }\end{array}$ & 99 \\
Level II & $\begin{array}{l}\text { Malignant melanocytes infiltrate papillary } \\
\text { dermis singly or in small nests }\end{array}$ & 95 \\
\hline Level III & $\begin{array}{l}\text { Malignant melanocytes fill and expand } \\
\text { papillary dermis, with extension of tumor to } \\
\text { papillary-reticular dermal interface (usually } \\
\text { signifying vertical growth phase) }\end{array}$ & 82 \\
\hline Level IV & $\begin{array}{l}\text { Malignant melanocytes infiltrate reticular } \\
\text { dermis in significant fashion }\end{array}$ & 71 \\
Level V & $\begin{array}{l}\text { Malignant melanocytes infiltrate } \\
\text { subcutaneous fat }\end{array}$ & 49 \\
\hline
\end{tabular}

Table 4. Breslow Level.

\begin{tabular}{ll}
\hline Clark Level & Degree of Tumor Invasion \\
\hline Level I & $<1 \mathrm{~mm}$ \\
Level II & $1-2 \mathrm{~mm}$ \\
Level III & $>2-4 \mathrm{~mm}$ \\
Level IV & $>4 \mathrm{~mm}$ \\
\hline
\end{tabular}

Table 5. American Joint Committee on Cancer (AJCC) TNM Staging System for Melanoma (7th ed., 2010).

\begin{tabular}{|c|c|c|c|}
\hline \multicolumn{4}{|c|}{ Primary Tumor $(T)$} \\
\hline TX & \multicolumn{3}{|c|}{ Primary tumor cannot be assessed (eg, curettaged or severely } \\
\hline T0 & \multicolumn{3}{|c|}{ No evidence of primary tumor } \\
\hline Tis & \multicolumn{3}{|c|}{ Melanoma in situ } \\
\hline T1 & \multicolumn{3}{|c|}{ Melanomas $1.0 \mathrm{~mm}$ or less in thickness } \\
\hline $\mathrm{T} 2$ & \multicolumn{3}{|c|}{ Melanomas $1.01--2.0 \mathrm{~mm}$} \\
\hline T3 & \multicolumn{3}{|c|}{ Melanomas $2.01--4.0 \mathrm{~mm}$} \\
\hline T4 & \multicolumn{3}{|c|}{ Melanomas more than $4.0 \mathrm{~mm}$} \\
\hline \multicolumn{4}{|c|}{$\begin{array}{l}\text { Note: } a \text { and } b \text { sub categories of } \mathrm{T} \text { are assigned based on ulceration and } \\
\text { number of mitoses per } \mathrm{mm} 2 \text { as shown below: }\end{array}$} \\
\hline \multicolumn{2}{|c|}{$\mathrm{T}$ classification } & $\begin{array}{l}\text { Thickness } \\
(\mathrm{mm})\end{array}$ & Ulceration Status/Mitoses \\
\hline \multirow[t]{2}{*}{$\mathrm{T} 1$} & & $\mathrm{~T} 1 \leq 1.0$ & a: w/o ulceration and mitosis $<1 / \mathrm{mm} 2$ \\
\hline & & & b: with ulceration ormitoses $\geq 1 / \mathrm{mm} 2$ \\
\hline \multirow[t]{2}{*}{$\mathrm{T} 2$} & & T2 $1.01-2.0$ & a: w/o ulceration \\
\hline & & & b: with ulceration \\
\hline \multirow[t]{2}{*}{$\mathrm{T} 3$} & & T3 2.01-4.0 & a: w/o ulceration \\
\hline & & & b: with ulceration \\
\hline \multirow[t]{2}{*}{$\mathrm{T} 4$} & & $\mathrm{~T} 4>4.0$ & a: w/o ulceration \\
\hline & & & b: with ulceration \\
\hline
\end{tabular}

Table 6. American Joint Committee on Cancer (AJCC) TNM Staging System for Melanoma (7th ed., 2010).

\begin{tabular}{|c|c|c|}
\hline \multicolumn{3}{|c|}{ Regional Lymph Nodes (N) } \\
\hline NX & \multicolumn{2}{|c|}{$\begin{array}{l}\text { Patients in whom the regional lymph nodes cannot be } \\
\text { assessed (eg, previously removed for another reason) }\end{array}$} \\
\hline No & \multicolumn{2}{|c|}{ No regional metastases detected } \\
\hline N1-3 & \multicolumn{2}{|c|}{$\begin{array}{l}\text { Regional metastases based upon the number of metastatic } \\
\text { nodes and presence or absence of intralymphatic } \\
\text { metastases (in transit or satellite metastases) }\end{array}$} \\
\hline \multicolumn{3}{|c|}{ Note: N1-3 and a-c sub categories are assigned as shown below: } \\
\hline $\begin{array}{l}\mathrm{N} \\
\text { Classification }\end{array}$ & $\begin{array}{l}\text { No. of Metastatic Nodes } \\
\text { Nodal Metastatic Mass }\end{array}$ & Nodal Metastatic Mass \\
\hline N1 & 1 node & $\begin{array}{l}\text { a: micrometastasis* } \\
\text { b: macrometastasis** }\end{array}$ \\
\hline $\mathrm{N} 2$ & $2-3$ nodes & $\begin{array}{l}\text { a: micrometastasis* } \\
\text { b: macrometastasis** } \\
\text { c: in transit } \\
\text { met(s)/satellite(s) without } \\
\text { metastatic nodes }\end{array}$ \\
\hline N3 & $\begin{array}{l}4 \text { or more metastatic nod } \\
\text { met(s)/satellite(s) with m }\end{array}$ & $\begin{array}{l}r \text { matted nodes, or in transit } \\
\text { tatic node(s) }\end{array}$ \\
\hline
\end{tabular}

*Micrometastases are diagnosed after sentinel lymph node biopsy and completion lymphadenectomy (if performed).

**Macrometastases are defined as clinically detectable nodal metastases confirmed by therapeutic lymphadenectomy or when nodal metastasis exhibits gross extracapsular extension. 
Table 7. American Joint Committee on Cancer (AJCC) TNM Staging System for Melanoma (7th ed., 2010).

\begin{tabular}{lll}
\hline \multicolumn{2}{l}{ Distant Metastasis (M) } \\
\hline M0 & No detectable evidence of distant metastases \\
M1a & Metastases to skin, subcutaneous, or distant lymph nodes \\
M1b & Metastases to lung \\
M1c & Metastases to all other visceral sites or distant metastases \\
Note: Serum LDH is incorporated into the M category as shown below: \\
to any site combined with an elevated serum LDH \\
Classification & Site & Serum LDH \\
M1a & Distant skin, subcutaneous, or nodal mets & Normal \\
M1b & Lung metastases & Normal \\
M1c & All other visceral metastases & Normal \\
& Any distant metastasis & Elevated \\
\hline
\end{tabular}

Table 8. American Joint Committee on Cancer (AJCC) TNM Staging System for Melanoma (7th ed., 2010).

\begin{tabular}{llll}
\hline \multicolumn{2}{l}{ Anatomic Stage/Prognostic Groups } & & \\
\hline Clinical Staging* & & & \\
\hline Stage 0 & Tis & N0 & M0 \\
Stage IA & T1a & N0 & M0 \\
Stage IB & T1b & N0 & M0 \\
& T2a & N0 & M0 \\
Stage IIA & T2b & N0 & M0 \\
& T3a & N0 & M0 \\
Stage IIB & T3b & N0 & M0 \\
& T4a & N0 & M0 \\
Stage IIC & T4b & N0 & M0 \\
Stage III & Any T & $\geq$ N1 & M0 \\
Stage IV & Any T & Any N & M1 \\
\hline
\end{tabular}

*Clinical staging includes microstaging of the primary melanoma and clinical/radiologic evaluation for metastases. By convention, it should be used after complete excision of the primary melanoma with clinical assessment for regional and distant metastases.

Table 9. American Joint Committee on Cancer (AJCC) TNM Staging System for Melanoma (7th ed., 2010).

\begin{tabular}{|c|c|c|c|}
\hline \multicolumn{4}{|c|}{ Pathologic Staging** } \\
\hline Stage 0 & Tis & N0 & M0 \\
\hline Stage IA & T1a & No & M0 \\
\hline \multirow[t]{2}{*}{ Stage IB } & $\mathrm{T} 1 \mathrm{~b}$ & No & M0 \\
\hline & $\mathrm{T} 2 \mathrm{a}$ & No & M0 \\
\hline \multirow[t]{2}{*}{ Stage IIA } & $\mathrm{T} 2 \mathrm{~b}$ & No & M0 \\
\hline & T3a & No & M0 \\
\hline \multirow[t]{2}{*}{ Stage IIB } & $\mathrm{T} 3 \mathrm{~b}$ & No & M0 \\
\hline & $\mathrm{T} 4 \mathrm{a}$ & No & M0 \\
\hline Stage IIC & $\mathrm{T} 4 \mathrm{~b}$ & No & M0 \\
\hline \multirow[t]{2}{*}{ Stage IIIA } & $\mathrm{T}(1-4) \mathrm{a}$ & $\mathrm{N} 1 \mathrm{a}$ & M0 \\
\hline & $\mathrm{T}(1-4) \mathrm{a}$ & $\mathrm{N} 2 \mathrm{a}$ & M0 \\
\hline \multirow[t]{5}{*}{ Stage IIIB } & $\mathrm{T}(1-4) \mathrm{b}$ & N1a & M0 \\
\hline & $\mathrm{T}(1-4) \mathrm{b}$ & $\mathrm{N} 2 \mathrm{a}$ & M0 \\
\hline & $\mathrm{T}(1-4) \mathrm{a}$ & N1b & M0 \\
\hline & $\mathrm{T}(1-4) \mathrm{a}$ & $\mathrm{N} 2 \mathrm{~b}$ & M0 \\
\hline & $\mathrm{T}(1-4) \mathrm{a}$ & $\mathrm{N} 2 \mathrm{c}$ & M0 \\
\hline \multirow[t]{4}{*}{ Stage IIIC } & $\mathrm{T}(1-4) \mathrm{b}$ & $\mathrm{N} 1 \mathrm{~b}$ & M0 \\
\hline & $\mathrm{T}(1-4) \mathrm{b}$ & $\mathrm{N} 2 \mathrm{~b}$ & M0 \\
\hline & $\mathrm{T}(1-4) \mathrm{b}$ & $\mathrm{N} 2 \mathrm{c}$ & M0 \\
\hline & Any $T$ & $\mathrm{~N} 3$ & M0 \\
\hline Stage IV & Any T & Any N & M1 \\
\hline
\end{tabular}

\section{Conclusions}

Cutaneous malignancies like basal cell carcinoma (BCC), squamous cell carcinoma (SCC) and melanoma of the skin constitute one of the most commonly diagnosed cancers in the United States of America (USA). Cutaneous melanoma accounts for $4 \%$ of all skin cancers diagnosis but accounts for $75 \%$ of skin cancer deaths. Physicians need to have an up to date knowledge about the epidemiology, risk factors, and clinical features in order to make an early diagnosis and provide appropriate management decision to improve survival in this aggressive malignancy.

\section{References}

[1] Siegel, R., et al., Cancer statistics, 2014. CA Cancer J Clin, 2014. 64(1): p. 9-29.

[2] Cancer Facts and Figures 2015., in American Cancer Society. 2015, American Cancer Society: Atlanta.

[3] Siegel, R., D. Naishadham, and A. Jemal, Cancer statistics, 2014. CA Cancer J Clin, 2014. 63(1): p. 11-30.

[4] Jemal, A., et al., Recent trends in cutaneous melanoma incidence and death rates in the United States, 1992-2006. J Am Acad Dermatol, 2011. 65(5 Suppl 1): p. S17-25 e1-3.

[5] Sheets, S. S. F., Melanoma of the Skin. 2013.

[6] Society, A. C., Cancer Facts and Figures 2013.

[7] Edwards, B. K., et al., Annual Report to the Nation on the status of cancer, 1975-2010, featuring prevalence of comorbidity and impact on survival among persons with lung, colorectal, breast, or prostate cancer. Cancer, 2013.

[8] Parkin, D. M., D. Mesher, and P. Sasieni, 13. Cancers attributable to solar (ultraviolet) radiation exposure in the UK in 2010. Br J Cancer, 2011. 105 Suppl 2: p. S66-9.

[9] Robinson, J. K., Sun exposure, sun protection, and vitamin D. JAMA, 2005. 294(12): p. 1541-3.

[10] Rigel, D. S., J. Russak, and R. Friedman, The evolution of melanoma diagnosis: 25 years beyond the ABCDs. CA Cancer J Clin, 2010. 60(5): p. 301-16.

[11] Desmond, R. A. and S. J. Soong, Epidemiology of malignant melanoma. Surg Clin North Am, 2003. 83(1): p. 1-29.

[12] Greenlee, R. T., et al., Cancer statistics, 2001. CA Cancer J Clin, 2001. 51(1): p. 15-36.

[13] Ries LA, E. M., Kosary CL, et al., SEER Cancer Statistics Review, 1973-1999. 2002: Bethesda, Maryland.

[14] Surveillance, E., and End Results Program 1975-2004, FIve Year Survival Rates Based on Follow up of Patients Through 2004, D.o.C.C.a.P. Sciences, Editor. 2007: National Cancer Institute.

[15] Ries LAG, M. D., Krapcho, M, et al. (eds). SEER Cancer Statistics Review, 1975-2009 (Vintage 2009 Populations), N. C. Institute, Editor. 2004: Bethesda, MD.

[16] Thompson, J. F., R. A. Scolyer, and R. F. Kefford, Cutaneous melanoma. Lancet, 2005. 365(9460): p. 687-701. 
[17] Pfeifer, G. P., Y. H. You, and A. Besaratinia, Mutations induced by ultraviolet light. Mutat Res, 2005. 571(1-2): p. 19-31.

[18] Pfeifer, G. P. and A. Besaratinia, UV wavelength-dependent DNA damage and human non-melanoma and melanoma skin cancer. Photochem Photobiol Sci, 2012. 11(1): p. 90-7.

[19] Cogliano, V. J., et al., Preventable exposures associated with human cancers. J Natl Cancer Inst, 2011. 103(24): p. 1827-39.

[20] Cancer, I. A. f. R. o., Solar and ultraviolet radiation. Monographs on the Evaluation of Carcinogenic Risks to Humans. 1992, Lyon: IARCPress.

[21] Dennis, L. K., et al., Sunburns and risk of cutaneous melanoma: does age matter? A comprehensive meta-analysis. Ann Epidemiol, 2008. 18(8): p. 614-27.

[22] Neale, R. E., et al., Site-specific occurrence of nonmelanoma skin cancers in patients with cutaneous melanoma. $\mathrm{Br} \mathrm{J}$ Cancer, 2005. 93(5): p. 597-601.

[23] Zanetti, R., et al., Comparison of risk patterns in carcinoma and melanoma of the skin in men: a multi-centre case-casecontrol study. Br J Cancer, 2006. 94(5): p. 743-51.

[24] Nelemans, P. J., et al., An addition to the controversy on sunlight exposure and melanoma risk: a meta-analytical approach. J Clin Epidemiol, 1995. 48(11): p. 1331-42.

[25] Elwood, J. M. and J. Jopson, Melanoma and sun exposure: an overview of published studies. Int J Cancer, 1997. 73(2): p. 198-203.

[26] Gandini, S., et al., Meta-analysis of risk factors for cutaneous melanoma: III. Family history, actinic damage and phenotypic factors. Eur J Cancer, 2005. 41(14): p. 2040-59.

[27] Scherer, D. and R. Kumar, Genetics of pigmentation in skin cancer--a review. Mutat Res, 2010. 705(2): p. 141-53.

[28] Fitzpatrick, T. B., The validity and practicality of sun-reactive skin types I through VI. Arch Dermatol, 1988. 124(6): p. 86971 .

[29] Pelucchi, C., et al., Risk factors for histological types and anatomic sites of cutaneous basal-cell carcinoma: an italian case-control study. J Invest Dermatol, 2007. 127(4): p. 935-44.

[30] Gallagher, R. P., et al., Sunlight exposure, pigmentary factors, and risk of nonmelanocytic skin cancer. I. Basal cell carcinoma. Arch Dermatol, 1995. 131(2): p. 157-63.

[31] Olsen, C. M., H. J. Carroll, and D. C. Whiteman, Estimating the attributable fraction for melanoma: a meta-analysis of pigmentary characteristics and freckling. Int J Cancer, 2010. 127(10): p. 2430-45.

[32] Williams, P. F., et al., Melanocortin 1 receptor and risk of cutaneous melanoma: a meta-analysis and estimates of population burden. Int J Cancer, 2011. 129(7): p. 1730-40.

[33] Bauer, J. and C. Garbe, Acquired melanocytic nevi as risk factor for melanoma development. A comprehensive review of epidemiological data. Pigment Cell Res, 2003. 16(3): p. 297306.

[34] Gerstenblith, M. R., et al., Basal cell carcinoma and anthropometric factors in the U.S. radiologic technologists cohort study. Int J Cancer, 2012. 131(2): p. E149-55.

[35] Gerstenblith, M. R., J. Shi, and M. T. Landi, Genome-wide association studies of pigmentation and skin cancer: a review and meta-analysis. Pigment Cell Melanoma Res, 2010. 23(5): p. 587-606.

[36] Ting, W. H., et al., Clinical and laboratory characteristics of type 1 diabetes in children and adolescents: experience from a medical center. Acta Paediatr Taiwan, 2007. 48(3): p. 119-24.

[37] Kiiski, V., et al., Risk factors for single and multiple basal cell carcinomas. Arch Dermatol, 2010. 146(8): p. 848-55.

[38] Lachiewicz, A. M., et al., Epidemiologic support for melanoma heterogeneity using the Surveillance, Epidemiology, and End Results Program. J Invest Dermatol, 2008. 128(1): p. 243-5.

[39] Little, E. G. and M. J. Eide, Update on the current state of melanoma incidence. Dermatol Clin, 2012. 30(3): p. 355-61.

[40] Ting, W., et al., Tanning bed exposure increases the risk of malignant melanoma. Int J Dermatol, 2007. 46(12): p. 1253-7.

[41] Monograph, S. A., Cancer Epidemiology in Older Adolescentes and Young Adults. 2007: p. 53-57.

[42] Linos, E., et al., Increasing burden of melanoma in the United States. J Invest Dermatol, 2009. 129(7): p. 1666-74.

[43] El Ghissassi, F., et al., A review of human carcinogens--part D: radiation. Lancet Oncol, 2009. 10(8): p. 751-2.

[44] Wehner, M. R., et al., Indoor tanning and non-melanoma skin cancer: systematic review and meta-analysis. BMJ, 2012. 345: p. e5909.

[45] Kwon, H. T., et al., Promotion of frequent tanning sessions by indoor tanning facilities: two studies. J Am Acad Dermatol, 2002. 46(5): p. 700-5.

[46] Demierre, M. F., Time for the national legislation of indoor tanning to protect minors. Arch Dermatol, 2003. 139(4): p. $520-4$.

[47] Boniol, M., et al., Cutaneous melanoma attributable to sunbed use: systematic review and meta-analysis. BMJ, 2012. 345: p. e4757.

[48] BA., G., Skin and aging process. CRC Press., 1984. 124.

[49] Abbasi, N. R., et al., Early diagnosis of cutaneous melanoma: revisiting the ABCD criteria. JAMA, 2004. 292(22): p. 27716.

[50] Rhodes, A. R., et al., Risk factors for cutaneous melanoma. A practical method of recognizing predisposed individuals. JAMA, 1987. 258(21): p. 3146-54.

[51] Dulon, M., et al., Sun exposure and number of nevi in 5- to 6year-old European children. J Clin Epidemiol, 2002. 55(11): p. 1075-81.

[52] Wachsmuth, R. C., et al., Heritability and gene-environment interactions for melanocytic nevus density examined in a U.K. adolescent twin study. J Invest Dermatol, 2001. 117(2): p. 348-52.

[53] Tsao, H., M. B. Atkins, and A. J. Sober, Management of cutaneous melanoma. N Engl J Med, 2004. 351(10): p. 9981012.

[54] Gandini, S., et al., Meta-analysis of risk factors for cutaneous melanoma: I. Common and atypical naevi. Eur J Cancer, 2005. 41(1): p. 28-44. 
[55] Olsen, C. M., H. J. Carroll, and D. C. Whiteman, Estimating the attributable fraction for cancer: A meta-analysis of nevi and melanoma. Cancer Prev Res (Phila), 2010. 3(2): p. 23345 .

[56] Greene, M. H., et al., High risk of malignant melanoma in melanoma-prone families with dysplastic nevi. Ann Intern Med, 1985. 102(4): p. 458-65.

[57] Reimer, R. R., et al., Precursor lesions in familial melanoma. A new genetic preneoplastic syndrome. JAMA, 1978. 239(8): p. 744-6.

[58] Clark, W. H., Jr., et al., Origin of familial malignant melanomas from heritable melanocytic lesions. 'The B-K mole syndrome'. Arch Dermatol, 1978. 114(5): p. 732-8.

[59] Lynch, H. T., T. G. Shaw, and J. F. Lynch, Inherited predisposition to cancer: a historical overview. Am J Med Genet C Semin Med Genet, 2004. 129C(1): p. 5-22.

[60] Bishop, D. T., et al., Geographical variation in the penetrance of CDKN2A mutations for melanoma. J Natl Cancer Inst, 2002. 94(12): p. 894-903.

[61] Balamurugan, A., et al., Subsequent primary cancers among men and women with in situ and invasive melanoma of the skin. J Am Acad Dermatol, 2011. 65(5 Suppl 1): p. S69-77.

[62] Bradford, P. T., et al., Increased risk of second primary cancers after a diagnosis of melanoma. Arch Dermatol, 2010. 146(3): p. 265-72.

[63] Yang, G. B., et al., Risk and survival of cutaneous melanoma diagnosed subsequent to a previous cancer. Arch Dermatol, 2011. 147(12): p. 1395-402.

[64] Goggins, W., W. Gao, and H. Tsao, Association between female breast cancer and cutaneous melanoma. Int J Cancer, 2004. 111(5): p. 792-4.

[65] Liu, H., K. Hemminki, and J. Sundquist, Renal cell carcinoma as first and second primary cancer: etiological clues from the Swedish Family-Cancer Database. J Urol, 2011. 185(6): p. 2045-9.

[66] Pirani, M., et al., Risk for second malignancies in nonHodgkin's lymphoma survivors: a meta-analysis. Ann Oncol, 2011. 22(8): p. 1845-58.

[67] Morton, L. M., et al., Second malignancy risks after nonHodgkin's lymphoma and chronic lymphocytic leukemia: differences by lymphoma subtype. J Clin Oncol, 2010. 28(33): p. $4935-44$.

[68] Braam, K. I., et al., Malignant melanoma as second malignant neoplasm in long-term childhood cancer survivors: a systematic review. Pediatr Blood Cancer, 2012. 58(5): p. 66574.

[69] Law, M. H., S. Macgregor, and N. K. Hayward, Melanoma genetics: recent findings take us beyond well-traveled pathways. J Invest Dermatol, 2012. 132(7): p. 1763-74.

[70] Hansen, C. B., et al., Clinical germline genetic testing for melanoma. Lancet Oncol, 2004. 5(5): p. 314-9.

[71] Begg, C. B., et al., Lifetime risk of melanoma in CDKN2A mutation carriers in a population-based sample. J Natl Cancer Inst, 2005. 97(20): p. 1507-15.

[72] Cachia, A. R., et al., CDKN2A mutation and deletion status in thin and thick primary melanoma. Clin Cancer Res, 2000. 6(9): p. 3511-5.

[73] Garcia-Borron, J. C., B. L. Sanchez-Laorden, and C. JimenezCervantes, Melanocortin-1 receptor structure and functional regulation. Pigment Cell Res, 2005. 18(6): p. 393-410.

[74] Ha, T., et al., Defining the quantitative contribution of the melanocortin 1 receptor (MC1R) to variation in pigmentary phenotype. Ann N Y Acad Sci, 2003. 994: p. 339-47.

[75] Duffy, D. L., et al., Interactive effects of MC1R and OCA2 on melanoma risk phenotypes. Hum Mol Genet, 2004. 13(4): p. 447-61.

[76] Healy, E., Melanocortin 1 receptor variants, pigmentation, and skin cancer susceptibility. Photodermatol Photoimmunol Photomed, 2004. 20(6): p. 283-8.

[77] Landi, M. T., et al., MC1R germline variants confer risk for BRAF-mutant melanoma. Science, 2006. 313(5786): p. 521-2.

[78] Cao, J., et al., MC1R is a potent regulator of PTEN after UV exposure in melanocytes. Mol Cell, 2013. 51(4): p. 409-22.

[79] Carey, W. P., Jr., et al., Dysplastic nevi as a melanoma risk factor in patients with familial melanoma. Cancer, 1994. 74(12): p. 3118-25.

[80] Schneider, K. G., Li-Fraumeni Syndrome, in Pagon RA BT, Dolan CR, et al., editors, ed. GeneReviews TM (Internet). 1999, University of Washington: Seattle (WA).

[81] Martorano, L. M., et al., Ocular melanoma and the BAPI hereditary cancer syndrome: implications for the dermatologist. Int J Dermatol, 2014. 53(6): p. 657-63.

[82] Said, S., et al., Primary central nervous system amelanotic melanoma in a Hispanic male: Case report. Pol J Radiol, 2014. 79: p. 199-202.

[83] Khalid, U., et al., Pathogenesis, diagnosis and management of primary melanoma of the colon. World J Surg Oncol, 2011. 9: p. 14.

[84] Schoneveld, M., et al., Intussusception of the small intestine caused by a primary melanoma? Case Rep Gastroenterol, 2012. 6(1): p. 15-9.

[85] Haskaraca, M. F., et al., Primary malignant melanoma of the gallbladder: a case report and review of the literature. Case Rep Surg, 2012. 2012: p. 693547.

[86] Friedman, R. J., D. S. Rigel, and A. W. Kopf, Early detection of malignant melanoma: the role of physician examination and self-examination of the skin. CA Cancer J Clin, 1985. 35(3): p. 130-51.

[87] Grin, C. M., et al., Accuracy in the clinical diagnosis of malignant melanoma. Arch Dermatol, 1990. 126(6): p. 763-6.

[88] MacKie, R. M., et al., The number and distribution of benign pigmented moles (melanocytic naevi) in a healthy British population. Br J Dermatol, 1985. 113(2): p. 167-74.

[89] Argenziano, G., et al., Seven-point checklist of dermoscopy revisited. Br J Dermatol, 2011. 164(4): p. 785-90.

[90] MacKie, R. M., Clinical recognition of early invasive malignant melanoma. BMJ, 1990. 301(6759): p. 1005-6. 
[91] Excellence, N. I. f. H. a. C., Referral Guidelines for Suspected Cancer (NICE), N.I.f.H.a.C. Excellence, Editor. 2005: London.

[92] Grob, J. J. and J. J. Bonerandi, The 'ugly duckling' sign: identification of the common characteristics of nevi in an individual as a basis for melanoma screening. Arch Dermatol, 1998. 134(1): p. 103-4.

[93] Gachon, J., et al., First prospective study of the recognition process of melanoma in dermatological practice. Arch Dermatol, 2005. 141(4): p. 434-8.

[94] Vestergaard, M. E., et al., Dermoscopy compared with naked eye examination for the diagnosis of primary melanoma: a meta-analysis of studies performed in a clinical setting. $\mathrm{Br} \mathrm{J}$ Dermatol, 2008. 159(3): p. 669-76.

[95] Network, N. C. C., Melanoma. 2004, NCCN Guidelines.

[96] Bichakjian, C. K., et al., Guidelines of care for the management of primary cutaneous melanoma. American Academy of Dermatology. J Am Acad Dermatol, 2011. 65(5): p. $1032-47$

[97] Zettersten, E., et al., Prognostic factors in primary cutaneous melanoma. Surg Clin North Am, 2003. 83(1): p. 61-75.

[98] McGovern, V. J., H. M. Shaw, and G. W. Milton, Prognosis in patients with thin malignant melanoma: influence of regression. Histopathology, 1983. 7(5): p. 673-80.

[99] Slingluff, C. L., Jr., et al., Lethal thin"malignant melanoma. Identifying patients at risk. Ann Surg, 1988. 208(2): p. 150-61.

[100] Mihm, M. C., Jr., C. G. Clemente, and N. Cascinelli, Tumor infiltrating lymphocytes in lymph node melanoma metastases: a histopathologic prognostic indicator and an expression of local immune response. Lab Invest, 1996. 74(1): p. 43-7.

[101] Slater, D., Standards and Datasets for Reporting Cancers Dataset for Histological Reporting of Primary Cutaneous Malignant Melanoma and Regional Lymph Nodes, T.R.C.o. Pathologist, Editor. 2014: Carlton House Terrace, London, SW1Y 5AF. p. 1-35.

[102] Stojadinovic, A., et al., Value of frozen-section analysis of sentinel lymph nodes for primary cutaneous malignant melanoma. Ann Surg, 2002. 235(1): p. 92-8.

[103] Koopal, S. A., et al., Frozen section analysis of sentinel lymph nodes in melanoma patients. Cancer, 2000. 89(8): p. 1720-5.

[104] Tanis, P. J., et al., Frozen section investigation of the sentinel node in malignant melanoma and breast cancer. Ann Surg Oncol, 2001. 8(3): p. 222-6.

[105] Scolyer, R. A., et al., Pathologic examination of sentinel lymph nodes from melanoma patients. Semin Diagn Pathol, 2008. 25(2): p. 100-11.

[106] McGovern, V. J., et al., The classification of malignant melanoma and its histologic reporting. Cancer, 1973. 32(6): p. 1446-57.
[107] Jelfs, P. L., et al., Cutaneous malignant melanoma in Australia, 1989. Med J Aust, 1994. 161(3): p. 182-7.

[108] Langley RG, F. T., Sober, Balch, CM Houghton AN, Sober AJ, et al., Clinical characteristics in Cutaneous Melanoma. AJ Quality Medical Publishing, 1998: p. 81.

[109] Price, N. M., A. M. Rywlin, and A. B. Ackerman, Histologic criteria for the diagnosis of superficial spreading malignant melanoma: formulated on the basis of proven metastatic lesions. Cancer, 1976. 38(6): p. 2434-41.

[110] Liu, V. and M. C. Mihm, Pathology of malignant melanoma. Surg Clin North Am, 2003. 83(1): p. 31-60, v.

[111] Clark, W. H., Jr., et al., The histogenesis and biologic behavior of primary human malignant melanomas of the skin. Cancer Res, 1969. 29(3): p. 705-27.

[112] Clark, W. H., Jr., D. E. Elder, and M. Van Horn, The biologic forms of malignant melanoma. Hum Pathol, 1986. 17(5): $\mathrm{p}$. 443-50.

[113] Clark, W. H., Jr. and M. C. Mihm, Jr., Lentigo maligna and lentigo-maligna melanoma. Am J Pathol, 1969. 55(1): p. 3967.

[114] Weinstock, M. A. and A. J. Sober, The risk of progression of lentigo maligna to lentigo maligna melanoma. Br J Dermatol, 1987. 116(3): p. 303-10.

[115] Cohen, L. M., Lentigo maligna and lentigo maligna melanoma. J Am Acad Dermatol, 1995. 33(6): p. 923-36; quiz 937-40.

[116] Tannous, Z. S., et al., Progression to invasive melanoma from malignant melanoma in situ, lentigo maligna type. Hum Pathol, 2000. 31(6): p. 705-8.

[117] Coleman, W. P., 3rd, et al., Acral lentiginous melanoma. Arch Dermatol, 1980. 116(7): p. 773-6.

[118] Plotnick, H., N. Rachmaninoff, and H. J. VandenBerg, Jr., Polypoid melanoma: a virulent variant of nodular melanoma. Report of three cases and literature review. J Am Acad Dermatol, 1990. 23(5 Pt 1): p. 880-4.

[119] Mack, E. E. and E. C. Gomez, Neurotropic melanoma. A case report and review of the literature. J Neurooncol, 1992. 13(2): p. $165-71$.

[120] Cheng L, A. A., Desmoplastic Melanoma, Advances in Malignant Melanoma - Clinical and Research Perspectives. 2011.

[121] Breslow, A., Thickness, cross-sectional areas and depth of invasion in the prognosis of cutaneous melanoma. Ann Surg, 1970. 172(5): p. 902-8. 